\title{
A single step strategy to fabricate graphene fibres via electrochemical exfoliation for micro-supercapacitor applications \\ Dol:
}

10.1016/j.electacta.2019.01.034

\section{Document Version}

Accepted author manuscript

Link to publication record in Manchester Research Explorer

\section{Citation for published version (APA):}

He, D., Marsden, A. J., Li, Z., Zhao, R., Xue, W., \& Bissett, M. A. (2019). A single step strategy to fabricate graphene fibres via electrochemical exfoliation for micro-supercapacitor applications. Electrochimica Acta, 299, 645-653. https://doi.org/10.1016/j.electacta.2019.01.034

\section{Published in:}

Electrochimica Acta

\section{Citing this paper}

Please note that where the full-text provided on Manchester Research Explorer is the Author Accepted Manuscript or Proof version this may differ from the final Published version. If citing, it is advised that you check and use the publisher's definitive version.

\section{General rights}

Copyright and moral rights for the publications made accessible in the Research Explorer are retained by the authors and/or other copyright owners and it is a condition of accessing publications that users recognise and abide by the legal requirements associated with these rights.

\section{Takedown policy}

If you believe that this document breaches copyright please refer to the University of Manchester's Takedown Procedures [http://man.ac.uk/04Y6Bo] or contact uml.scholarlycommunications@manchester.ac.uk providing relevant details, so we can investigate your claim.

\section{OPEN ACCESS}




\title{
A single step strategy to fabricate graphene fibres via electrochemical exfoliation for micro-supercapacitor applications
}

\author{
Dongxu He, ${ }^{\text {ab }}$ Alexander J. Marsden, ${ }^{\mathrm{b}}$ Zheling Li, ${ }^{\mathrm{b}}$ Rui Zhao, ${ }^{\mathrm{a}}$ Weidong Xue, ${ }^{\mathrm{a}}$ and Mark A. Bissett ${ }^{\mathrm{b} *}$ \\ ${ }^{a}$ Institute of Applied Electrochemistry, School of Materials and Energy, University of Electronic \\ Science and Technology of China, Chengdu 610054, PR China. \\ ${ }^{b}$ School of Materials, National Graphene Institute, University of Manchester, Oxford Road, M13 9PL \\ Manchester, U.K \\ *E-mail:mark.bissett@manchester.ac.uk
}

\begin{abstract}
A green and low-cost method is presented to fabricate graphene fibre electrodes by electrochemical exfoliation of thin strips of graphite foil. When assembled into microsupercapacitors, the graphene fibres achieved an excellent electrochemical capacitance $(\sim$ $247.6 \mathrm{mF} \cdot \mathrm{cm}^{-2}$ at $\left.\sim 2 \mathrm{~mA} \cdot \mathrm{cm}^{-2}\right)$ and low equivalent series resistance $(\sim 2.4 \Omega)$, a significant improvement over the typically used graphene oxide based fibres. This excellent capacitive performance indicates these graphene-based energy storage devices could be ideal for microelectronics applications. Additionally, an all-solid-state flexible micro-supercapacitor was fabricated using a gel electrolyte $\left(\mathrm{H}_{3} \mathrm{PO}_{4} / \mathrm{PVA}\right)$ and exhibited a high areal capacitance of $70.6 \mathrm{mF} \cdot \mathrm{cm}^{-2}$ and a superior cycling stability of $\sim 96 \%$ capacitance retention after 2400 cycles, suggesting possible applications for flexible energy storage. The easily scalable and facile single step strategy presented here outperforms the conventionally used graphene oxide based methods, which typically require harmful chemicals and involve a more complex synthesis procedure.
\end{abstract}

\section{Keywords}

Supercapacitor, graphene, electrochemical exfoliation, solid-state electrolyte, flexible energy storage 


\section{Introduction}

The urgent need to improve energy conversion and storage efficiency continues to attract tremendous attention. ${ }^{1-13}$ One consensus identified in this field is the need to develop lightweight, wearable, low-cost and high performance supercapacitors. ${ }^{14-17}$ A variety of materials have been explored to fabricate supercapacitor electrodes and have achieved promising performance. Particularly, graphene and its derivatives have demonstrated versatile feasibility for use in supercapacitor electrodes. ${ }^{18-26}$ Graphene possesses outstanding physical and chemical properties, including high electrical conductivity and specific surface area, and therefore has been widely investigated as an electrode material for energy storage. ${ }^{27}$

One approach that has been previously used to assemble graphene into a practical architecture is the production of long thin fibres or ribbons with controlled structures. ${ }^{15,16,28-32}$ This method allows the translation of the beneficial properties of graphene, such as the high electrical conductivity and mechanical properties, into a macroscopic structure that better facilitates realworld applications. The methods previously exploited to achieve this goal include wet spinning of graphene oxide (GO) fibres, ${ }^{15,28,33,34}$ encapsulation of GO suspensions into a pipe-like template structure to direct assembly, ${ }^{29,35,36}$ and production of long flat ribbon-like structures from GO by modifying the wet spinning conditions. ${ }^{37}$ Notably these previously used methods typically rely on the use of GO suspensions which can ultimately hinder the properties of the resulting macroscopic assembly.

A wide variety of methods have been developed to prepare graphene and its derivatives since its discovery. ${ }^{38-41}$ For example, the growth of graphene by chemical vapour deposition (CVD) on metallic catalysts has been the most popular strategy to meet the requirement of larger size and higher quality. Chemically intercalated and exfoliated GO has been the most commonly used precursor for further fabrication of reduced graphene or graphene-based composites. ${ }^{42,43}$ The functional groups in GO can not only strongly affect its mechanical, electronic, and 
electrochemical properties, ${ }^{44}$ but can also provide multiple bonding sites for its processing and further derivatization. However, both CVD and GO-based chemical exfoliation methods are energy intensive and require large volumes of hazardous and toxic chemicals during the processing. Thus, alternative production methods should be investigated to avoid these issues. Electrochemical exfoliation of graphite has continued to attract attention recently due to its fast and easy nature. ${ }^{45}$ Various electrolyte solutions have been examined in the electrochemical exfoliation process to achieve graphene or graphene oxide flakes with greener methods, better quality and higher yields. ${ }^{38,46-50}$ However, for graphene's application in energy storage, additional conductive additives and polymer binders are typically needed for the fabrication of electrodes. These additives increase the cost and weight of the final assembled devices, and can also be detrimental to the energy and power density.

In this work, we present a one-step, green and facile method to directly fabricate macroscopic graphene fibres for use as electrodes in micro-supercapacitor applications, in which the electrodes are free of any additional additives or binders. Such fibre-like structures have previously been produced using a variety of techniques and shown to be promising for many different applications, but particularly for electrochemical energy storage. Aqueous ammonium persulfate (APS) was utilized as the electrolyte to electrochemically exfoliate thin strips of graphite foil. This process produced an expanded gallery of long thin graphene layers which we refer to as a graphene fibre (GF), and exhibited high electrochemical performance. This strategy not only greatly simplifies the process of fabricating graphene micro-supercapacitor electrodes but also provides a low-cost and scalable route for energy storage applications. 


\section{Experimental}

\subsection{Preparation of graphene fibres}

Commercial graphite foil (Gee graphite Ltd.) with a thickness of $0.5 \mathrm{~mm}$ was cut into thin strips and used directly as the working electrode. The electrochemical process was carried out with a Pt mesh counter electrode and a DC power supply (BK PRECISION 1688B). A length of about $40 \mathrm{~mm}$ of the graphite foil was immersed into aqueous ammonium persulphate $(0.1 \mathrm{M}, \geq 98 \%$, Aldrich) electrolyte and a constant voltage $(2.5 \mathrm{~V})$ was applied for several minutes. The products were washed with water and named as GFx (where $\mathrm{x}$ refer to the minutes number of exfoliation time, e.g. GF0 refers to the pristine graphite). The fibre was observed to expand to $\sim 1 \mathrm{~mm}$ ( 100\% increase) after 90 minutes of the exfoliation process, but reduces back to $\sim 0.8$ $\mathrm{mm}$ after drying.

\subsection{Fabrication of solid-state supercapacitor devices}

For the production of the solid-state devices a gel electrolyte $\left(\mathrm{H}_{3} \mathrm{PO}_{4} / \mathrm{PVA}\right)$ was prepared by mixing $1.0 \mathrm{~g} \mathrm{H}_{3} \mathrm{PO}_{4}(\geq 99.999 \%$, Aldrich) and 1.0 g PVA (poly(vinyl alcohol, Mw =89 00098000, 99+\% hydrolysed, Aldrich) in $10 \mathrm{~mL}$ deionized water and heated at $85 \mathrm{C}^{\circ}$ for $1 \mathrm{~h}$ under vigorous stirring. Afterward, $100 \mu \mathrm{L}$ of the $\mathrm{H}_{3} \mathrm{PO}_{4} / \mathrm{PVA}$ gel electrolyte was carefully drop-cast onto two parallel GF90 fibres on a supporting substrate.

\subsection{Electrochemical measurements}

For half-cell tests, three electrodes set up in $1.0 \mathrm{M} \mathrm{H}_{2} \mathrm{SO}_{4}$ aqueous solution were used, with $\mathrm{Pt}$ mesh and $\mathrm{Ag} / \mathrm{AgCl}$ electrode as the counter and reference electrode, respectively. All electrochemical tests were carried out using a COMPACTSTAT.h electrochemical workstation (Ivium Technologies). The electrochemical window for cyclic voltammetry (CV) measurements and galvanostatic charge-discharge tests was 0-0.8 V. Electrochemical impedance spectroscopy (EIS) analysis was performed in the frequency range of $10^{5}$ to $10^{-2} \mathrm{~Hz}$ 
with $10 \mathrm{mV}$ amplitude. The areal capacitance $\left(C_{A}\right)$ and volumetric capacitance $\left(C_{V}\right)$ were calculated based on the following equations:

$$
\begin{aligned}
& C_{A}=I \cdot \Delta t / A \cdot \Delta \mathrm{V} \\
& C_{V}=I \cdot \Delta t / V \cdot \Delta V \\
& \text { Or } \quad C_{A}=\frac{\int I(V) d V}{A \cdot v \cdot \Delta V}
\end{aligned}
$$

Where I is the applied working current, $v$ is the scan rate $\left(\mathrm{mV} \cdot \mathrm{s}^{-1}\right), \Delta t$ represents the discharge time and $\Delta \mathrm{V}$ is the voltage range, and $\mathrm{I}(\mathrm{V})$ is the voltammetric discharge current $(\mathrm{mA})$. For the three-electrode tests, $\mathrm{A}$ is the surface area of the electrode and V is the volume of the electrode. For the supercapacitor device, $\mathrm{A}$ and $\mathrm{V}$ refer to the total surface area $\left(\mathrm{cm}^{2}\right)$ of two electrodes and total volume of two electrodes, respectively.

\subsection{Characterization}

The morphology of the exfoliated graphene fibres was characterized using a scanning electron microscope (SEM, Philips XL30 FEGSEM) and transmission electron microscope (TEM, FEI Technai G2 20). Raman spectra were obtained by using a Raman spectrometer (inVia, Renishaw) equipped with a $532 \mathrm{~nm}(2.33 \mathrm{eV})$ laser. The Raman mapping was performed with a step of $5 \mu \mathrm{m}$ with a $\times 50$ objective. Crystal structure of the samples was investigated by $X-$ ray diffraction (XRD) with a PANalytical X'Pert Pro X'Celerator diffractometer. Surface area measurements (BET nitrogen adsorption isotherms) were carried out using a Quantachrome Quadrasorb SI instrument. 


\section{Results and Discussion}

Figure 1 schematically depicts the electrochemical exfoliation process, along with the corresponding SEM image of the fibre morphology. The cross section SEM image of the partially exfoliated graphite fibre in Figure 1(b) shows the stacked graphite layer structure, similar to the starting material seen in Figure 1(a). When a positive voltage (2.5 V) was applied to the graphite electrode, the graphite flakes begin to expand (shown mechanistically in Figure 1(c)). Before rinsing and drying, some residual APS crystals were observed and predominantly adhered to the edge of the graphene layers, as seen in Figure 1(d). After thorough rinsing the majority of this residue was removed and the final porous fibre structure was obtained as shown in Figure 1(e) and 1(f).

This work, as far as the authors are aware, demonstrates the first use of aqueous APS electrolyte to perform electrochemical exfoliation of graphite. The mechanism of the electrochemical exfoliation process has been recognized as: (i) the bias voltage results in the electrolysis of water and the radicals oxidize the edge or grain boundaries of the graphite $\left(\mathrm{H}_{2} \mathrm{O} \leftrightarrow \mathrm{OH}^{-}+\right.$ $\left.\mathrm{H}^{+}\right)$; (ii) the hydrolysis of APS occurs in the water $\left(\left(\mathrm{NH}_{4}\right)_{2} \mathrm{~S}_{2} \mathrm{O}_{8} \leftrightarrow 2 \mathrm{NH}_{4}^{+}+\mathrm{S}_{2} \mathrm{O}_{8}^{2-}, \mathrm{S}_{2} \mathrm{O}_{8}^{2-}+\right.$ $\left.2 \mathrm{H}_{2} \mathrm{O} \leftrightarrow 2 \mathrm{HSO}_{4}^{-}+\mathrm{H}_{2} \mathrm{O}_{2}, \mathrm{HSO}_{4}^{-} \leftrightarrow \mathrm{H}^{+}+\mathrm{SO}_{4}^{2-}\right)$, and the sulfate ions $\left(\mathrm{SO}_{4}^{2-}\right)$ and water intercalate in between the graphite layers; (iii) the further reduction of $\mathrm{SO}_{4}{ }^{2-}$ and electrolysis of water produces gas that expands the interlayer distance. ${ }^{38,51}$ With a continuous exfoliation process, the surface layer spacing expands and swells and this provides the channel for the electrolyte to access to the inner layers, yielding further exfoliation. But due to the simultaneous occurrence of oxidization, the edges can become curled and exfoliated more quickly than the expanding of the interlayers, i.e., the fibre can be exfoliated into thin graphene layers on the edges and maintain their connection to the inner graphite core, forming a coaxial structure. 
Through this layer expansion and exfoliation process, a low voltage gives priority to the exfoliation process and a highly connected coaxial-like structure was maintained. A variety of voltages have been investigated between $0-10 \mathrm{~V}$ to understand the different electrochemical behaviour. Considering the theoretical decomposition voltage of water and interfacial polarization in the process, there were no apparent changes occurring under $2 \mathrm{~V}$. With a bias voltage greater than $5 \mathrm{~V}$, severe bubbling was observed on the graphite electrode and disintegration of the fibre occurred. However, by maintaining a bias voltage under $3 \mathrm{~V}$ gentle bubbling was observed along with a visible expansion of the graphite, but no disintegration or dispersion of flakes into the electrolyte solution.

The effect of the exfoliation time on the resulting structure was also investigated with a constant bias voltage of $2.5 \mathrm{~V}$. With different exfoliation time $(0-120 \mathrm{mins})$, the changes of the morphology was observed by SEM as shown in Figure 2. Both the top-down and the crosssection SEM images of the original graphite show close packed layers (Figure 2(a) and (b)). When a voltage was applied to the GF for 30 mins, it expanded vertically and small wrinkles emerged on the surface of the electrode, as shown in Figure 2(c) and (d). When the exfoliation time was further increased to 60 mins both the top surface and side of the GF continued to expand further as shown in Figure 2(e) and (f). With continued exfoliation up to 90 mins, a porous and cross-linked surface and a honeycomb-like side view were observed in Figure 2 (g) and (h). Additional SEM images of the GF90 fibre are shown in Figure S1 with different magnifications and angles. However, with excessive exfoliation the connected threedimensional structure collapsed due to the continued interlayer expansion and removal of material from the electrode when the time increased to 120 mins (Figure 2 (i) and (j)). Additionally, optical images of the products are shown in Figure S2 depicting the free-standing fibre-like structure. 
The exfoliation process was further investigated by Raman spectroscopy. The GF0 in Figure 3(a) shows the typical Raman spectrum of graphite, with two characteristic peaks, one at 1580 $\mathrm{cm}^{-1}$ (G peak) and the other at $2714 \mathrm{~cm}^{-1}$ (2D peak). As seen in Figure 3(a) increasing the exfoliation time results in a notable increase of the $\mathrm{D}$ peak intensity at around $1350 \mathrm{~cm}^{-1}$. The presence of defects or disorder influences the intensity of D band, indicating a reduction of the crystallite grain size ${ }^{52-54}$ From the related SEM images shown previously in Figure 2, we can infer that continuous expansion causes the edges to curl, along with the increase of the number of edges, this contributes to the increase of the D band intensity. In addition, the two-phonon defect-assisted processes leads to the presence of a D+D' peak at $\sim 2950 \mathrm{~cm}^{-1}$, as observed in both GF90 and GF120. ${ }^{53}$ XRD characterisation was further carried out and also indicated that graphene was produced during the exfoliation process (Figure S3). Additionally, nitrogen (N) doping caused by the presence of the ammonium radical in the electrolyte during exfoliation can also have an influence on the electrochemical properties. XPS analysis was used to quantify the content and doping type of nitrogen (Figure S4), the content of nitrogen in GF90 and found it to be $\sim 1.1$ at.\% (Figure S5).

Raman mapping was carried out to investigate the structural coherence of the fibres. Raman line mapping (scanning across the fibre) was performed and Figure 3(b) shows the distribution of $G$ peak positions and ratios of $I_{g} / I_{d}$ for each sample. With increased exfoliation time $I_{g} / I_{d}$ decreased and the $G$ peak was red-shifted. This matched well with the SEM images, demonstrating a transition from graphite to graphene and a higher defect density due to $\mathrm{N}$ doping as reaction time increase. In addition, the distribution was narrower when the exfoliation time increased, indicating a more homogenous surface morphology of the fibre.

Brunauer-Emmett-Teller (BET) surface area analysis was carried out to further investigate the evolution of the GF structure. As shown in Figure 3(c), the BET surface area increases with increasing exfoliation time, as expected, in the range of 30-90 mins. The surface area 
significantly decreases while the time period reaches $120 \mathrm{mins}$ and this is attributed to structural collapse. The pore width distribution curves calculated by density functional theory (DFT) in Figure 3(d) indicate that GF90 and GF120 have similar mesopores $(2-50 \mathrm{~nm})$ structure. The mesopore distribution of the GF60, GF90 and GF120 is in the range of 3-5 nm. In addition, GF90 shows the richest mesopores content in Figure 3(d) and a pronounced hysteretic step in Figure 3(c), indicating a more complex pore geometry and related to the pore connectivity effects. ${ }^{55,56}$

To further analyse the characteristics of the individual graphene flakes a GF90 fibre was cut and sonicated in ethanol for 30 mins for TEM analysis to completely remove the outer graphene layers for analysis. As shown in Figure 3(e), the wrinkled thin layers were uniformly distributed on the substrate. A magnified image in Figure 3(f) reveals that the thin layers were partly restacked and wrinkled (the red circles highlight these wrinkles), which will not only maintain the three dimensional porous structure but also improve the conductivity of the fibre. The inset selected-area electron diffraction (SAED) of the thin layer shows the typical 6-fold symmetry of graphene. There are also extra spots nearby, and these can be related to the layer overlaps as highlighted in the red circles. Each of these characterization techniques supports that GF90 possesses a porous graphene nanostructure.

The electrochemical behaviour of different samples with increasing exfoliation time was evaluated by cyclic voltammetry (CV). Under a three-electrode system, their electrochemical performance is compared at a scan rate of $100 \mathrm{mV} \mathrm{s}^{-1}$ in Figure 4(a). Compared to the initial graphite fibre (GF0), the area of the related CV curve of GRx increases with increasing exfoliation time, as expected due to the production of a three dimensional surface structure with increasing surface area. However, the capacitance decreased after exfoliation for prolonged periods (120 mins), likely due to a reduction in surface area due to pore collapse as discussed previously. To further investigate the electrode performance electrochemical 
impedance spectroscopy (EIS) is presented in Figure 4(b). In the high-frequency region, the equivalent series resistance (ESR) of these graphene fibres was about $2.2 \Omega$ and this remained constant regardless of the changing exfoliation time, indicating that the fibre structure has favourable ion accessibility. A significant increase of the diffusion resistance was observed in the low-frequency region and that may sufficiently explain the area decrease of GF120 compared with GF90 (seen in Figure 4(a)). As discussed previously, excessive exfoliation damages the internal connection of the fibres and leads to the collapse of the honeycomb-like structure. The increase of diffusion resistance and decrease of surface area directly influences the electrochemical performance. The applied voltage and time period in the exfoliation process are two critical factors that greatly influence the resulting fibre structure and its electrochemical performance. Thus, it is necessary to optimize these factors in order to achieve the best possible device performance. Furthermore, the top inset in Figure $4 \mathrm{~b}$ is the equivalent circuit used for fitting the EIS data of GF90. The fitted parameters for the circuit elements is shown in Table S1. The solution resistance (Rs) describes the internal resistance of the electrode and the resistance of the electrolyte. The charge transfer resistance (Rct) represents the rate of redox reactions at the interface of the electrolyte and electrode. CPE is the constant phase element representing double layer capacitance.

We further investigated the half-cell performance of the GF90 by using a three-electrode system. The electrochemical behaviour was investigated and the cyclic voltammograms at different scan rates are shown in Figure S6. To confirm the electrochemical properties of GF90, galvanostatic charge-discharge measurements were applied at current densities of 2, 4, 10, 20 and $40 \mathrm{~mA} \cdot \mathrm{cm}^{-2}$ in Figure 4(c). The charge curves and their corresponding discharge curves were found to exhibit a typical symmetrical triangular shape without any obvious IR drop even at a higher current density, indicating low resistance and ideal double-layer capacitive behaviour. The specific areal capacitance $\left(\mathrm{C}_{\mathrm{a}}\right)$ and specific volumetric capacitance $\left(\mathrm{C}_{\mathrm{v}}\right)$ were 
calculated in Figure 4(d). The $\mathrm{C}_{\mathrm{A}}$ of GF90 was $\sim 247.6 \mathrm{mF} \cdot \mathrm{cm}^{-2}$ at $2 \mathrm{~mA} \cdot \mathrm{cm}^{-2}$, and decreased to $\sim 153.8 \mathrm{mF} \cdot \mathrm{cm}^{-2}$ at a higher current density of $40 \mathrm{~mA} \cdot \mathrm{cm}^{-2}$. Moreover, the $\mathrm{C}_{\mathrm{v}}$ of the CF90 ranges from $\sim 10.0$ to $\sim 16.1 \mathrm{~F} \cdot \mathrm{cm}^{-3}$ when the current density increased from 2 to $40 \mathrm{~mA} \cdot \mathrm{cm}^{-1}$.

Next, all-solid-state symmetric supercapacitor devices were fabricated by using two GF90 electrodes and a conducting gel electrolyte, as demonstrated previously. ${ }^{50}$ The electrochemical behaviour of the solid-state device was first examined by $\mathrm{CV}$ measurements at scan rates ranging from 2 to $200 \mathrm{mV} \cdot \mathrm{s}^{-1}$, as seen in Figure 5 (a) and (b). A typical electrical double-layer capacitive feature with a nearly rectangular shape was observed at lower scan rates. The supercapacitor shows $96 \%$ retention of its initial specific capacitance after 2400 cycles between $0 \mathrm{~V}$ and $0.8 \mathrm{~V}$ at a current density of $\sim 3 \mathrm{~mA} \cdot \mathrm{cm}^{-2}$. In addition, the coulombic efficiencies are $\sim 97 \%$, with a high areal capacitance of $\sim 45.2 \mathrm{mF} \cdot \mathrm{cm}^{-2}$ (Figure $5(\mathrm{c})$ ). This can also be confirmed by the charge-discharge curves in Figure S7 as there are no apparent changes even after thousands of cycles. The equivalent series resistance (ESR) of the device was calculated to be $21.6 \Omega$ based on the IR drop in the charge-discharge curve at $4 \mathrm{~mA} \cdot \mathrm{cm}^{-2}$ (Figure S7). Both the capacitance retention and coulombic efficiency are superior to previously published related works. ${ }^{57-59}$ The outstanding cycle stability and capacitance of the devices are likely related to the highly porous structure and high conductivity of the coaxial-like graphene fibre electrodes. The areal capacitance of the device was calculated as a function of scan rate from the CV results (black) and with increasing current density from the galvanostatic charge/discharge (red) and shown in Figure 5 (d). The inset optical images show two different devices with twisted and parallel structures and demonstrates the good mechanical flexibility of the graphene fibre supercapacitor devices. With increasing current density (red), the areal capacitance was calculated to be $\sim 70.6 \mathrm{mF} \cdot \mathrm{cm}^{-2}$ at a low current density of $\sim 0.3 \mathrm{~mA} \cdot \mathrm{cm}^{-2}$, and decreased to $\sim 15.4 \mathrm{mF} \cdot \mathrm{cm}^{-2}$ when the current density increased to $\sim 15 \mathrm{~mA} \cdot \mathrm{cm}^{-2}$. Calculating the areal capacitance from the CV curves (black) in Figure 5 (a) and (b), the areal capacitance 
ranges from $\sim 69.9 \mathrm{mF} \cdot \mathrm{cm}^{-2}$ to $\sim 32.4 \mathrm{mF} \cdot \mathrm{cm}^{-2}$ with increasing scan rates from 2 to $200 \mathrm{mV} \cdot \mathrm{s}^{-1}$. The electrochemical performance of the solid-state device was also tested while undergoing mechanical bending, the capacitance retention was found to be $87.5 \%$ at $90^{\circ}$ and $83.0 \%$ at $180^{\circ}$ (Figure S8). This indicates that such devices could be used in a variety of applications where flexible energy storage was required while undergoing mechanical deformation. Furthermore, the Nyquist plot of the fabricated all-solid-state device is shown in Figure S9, this was found to be stable with little change in the plot after 2000 cycles.

When we compare the performance of these devices to those previously published, as shown in Table 1, the GF90 device exhibits superior electrochemical performance and we can notice several key points. Firstly, the majority of previous works have fabricated fibre or ribbon electrodes by using graphene or GO powder as the precursor in a top-down method, and this is generally complex and time consuming. ${ }^{57,59-62}$ The strategy presented in this work simplifies the process into just a single step. Furthermore, a pipe-like template structure is often needed to form the fibre, ${ }^{29,63}$ or a backbone supporting structure is needed, ${ }^{36}$ or an additional current collector. ${ }^{60,64}$ The in-situ exfoliation method and self-supported structure presented here is not only low-cost but also exhibits a low ESR $(2.4 \Omega)$ by using the graphite core as the current collector in a coaxial-like structure. This ESR is lower than the previously demonstrated assembled reduced graphene oxide (rGO) electrodes by orders of magnitude. ${ }^{28,29,65}$ Also, the electrochemical production of thin expanded graphene fibre electrodes demonstrates a comparable or improved electrochemical capacitance to these previous graphene-based works and even higher than the capacitance of graphene-polymer or graphene/metal-oxide composites electrodes, indicating applicability to a wide variety of energy storage applications. 


\section{Conclusions}

We present a simple and easily scalable strategy to fabricate thin graphene fibre electrodes for high performance micro-supercapacitor applications. These graphene fibres consist of a graphite core and an exfoliated graphene sheath in a coaxial structure. This is a facile and lowcost top-down method to fabricate porous graphene fibre-like structures and is distinct from the widely used bottom-up processes which have used graphene oxide. This electrochemical exfoliation process also has the advantage of being free of any additional conductive additives, activated carbon, or binders. This simplicity allows the produced micro-supercapacitor devices to be easily scaled, and is limited only by the size of the graphite foil precursor. The areal capacitances of the graphene fibre were measured as $\sim 247.6 \mathrm{mF} \cdot \mathrm{cm}^{-2}$ at $\sim 2 \mathrm{~mA} \cdot \mathrm{cm}^{-2}$ and $\sim 70.6$ $\mathrm{mF} \cdot \mathrm{cm}^{-2}$ at $\sim 0.3 \mathrm{~mA} \cdot \mathrm{cm}^{-2}$ in a three-electrode system and a symmetrical solid-state supercapacitor, respectively. This represents a significant improvement over the values presented previously for most similar systems. Comparing with current commonly used methods, this work demonstrates a significantly simplified synthesis process, lower resistance, higher capacitance retention and coulombic efficiency, and ultrahigh specific capacitance. The excellent electrochemical performance can be attributed to the highly porous structure and good electronic conductivity and interconnectivity of the graphene sheets. This simple exfoliation method shows a significant improvement over wet-spinning of GO fibres presented previously both in terms of energy performance and simplicity of production. Finally, the machinable property of the precursor graphite foil opens up multiple applications, including flexible energy storage as demonstrated by the excellent performance of the solid-state supercapacitor device. 


\section{Acknowledgements}

We thank Yuling Zhuo, Richard Fields, Lewis Le Fevre and Edurne Redondo at the National Graphene Institute (UK) for their help with the initial tests. All research data supporting this publication are directly available within this publication, as well as available from the corresponding author upon reasonable request.

\section{References}

1. El-Kady, M. F.; Kaner, R. B., Scalable fabrication of high-power graphene microsupercapacitors for flexible and on-chip energy storage. Nat. Commun. 2013, 4, 1475.

2. $\quad$ El-Kady, M. F.; Strong, V.; Dubin, S.; Kaner, R. B., Laser Scribing of High-Performance and Flexible Graphene-Based Electrochemical Capacitors. Science 2012, 335, 1326-1330.

3. Wu, Z. S.; Parvez, K.; Feng, X.; Müllen, K., Graphene-Based In-Plane Micro-Supercapacitors with High Power and Energy Densities. Nat. Commun. 2013, 4, 2487.

4. $\quad$ Miller, J. R., Valuing Reversible Energy Storage. Science 2012, 335, 1312-1313.

5. Simon, P.; Gogotsi, Y., Capacitive Energy Storage in Nanostructured Carbon-Electrolyte Systems. Acc. Chem. Res. 2013, 46, 1094-1103.

6. Bonaccorso, F.; Colombo, L.; Yu, G.; Stoller, M.; Tozzini, V.; Ferrari, A. C.; Ruoff, R. S.; Pellegrini, V., Graphene, Related Two-Dimensional Crystals, and Hybrid Systems for Energy Conversion and Storage. Science 2015, 347.

7. Zhang, X.; Hou, L.; Ciesielski, A.; Samorì, P., 2D Materials Beyond Graphene for HighPerformance Energy Storage Applications. Adv. Energy Mater. 2016, 6, 1600671.

8. Balamurugan, J.; Karthikeyan, G.; Thanh, T. D.; Kim, N. H.; Lee, J. H., Facile synthesis of vanadium nitride/nitrogen-doped graphene composite as stable high performance anode materials for supercapacitors. J. Power Sources 2016, 308, 149-157.

9. Balamurugan, J.; Nguyen, T. T.; Aravindan, V.; Kim, N. H.; Lee, J. H., Flexible Solid-State Asymmetric Supercapacitors Based on Nitrogen-Doped Graphene Encapsulated Ternary MetalNitrides with Ultralong Cycle Life. Adv. Funct. Mater. 2018, 28, 1804663.

10. Li, N.; Huang, X.; Zhang, H.; Li, Y.; Wang, C., Transparent and Self-Supporting Graphene Films with Wrinkled- Graphene-Wall-Assembled Opening Polyhedron Building Blocks for High Performance Flexible/Transparent Supercapacitors. ACS Appl. Mater. Interfaces 2017, 9, 9763-9771.

11. Guo, M.; Balamurugan, J.; Li, X.; Kim, N. H.; Lee, J. H., Hierarchical 3D Cobalt-Doped $\mathrm{Fe}_{3} \mathrm{O}_{4}$ Nanospheres@NG Hybrid as an Advanced Anode Material for High-Performance Asymmetric Supercapacitors. Small 2017, 13, 1701275. 
12. Balamurugan, J.; Li, C.; Aravindan, V.; Kim, N. H.; Lee, J. H., Hierarchical Ni-Mo-S and NiFe-S Nanosheets with Ultrahigh Energy Density for Flexible All Solid-State Supercapacitors. Adv. Funct. Mater. 2018, 28, 1803287.

13. Balamurugan, J.; Thanh, T. D.; Kim, N. H.; Lee, J. H., Facile synthesis of 3D hierarchical Ndoped graphene nanosheet/cobalt encapsulated carbon nanotubes for high energy density asymmetric supercapacitors. J. Mater. Chem. A 2016, 4, 9555-9565.

14. Bae, J.; Song, M. K.; Park, Y. J.; Kim, J. M.; Liu, M.; Wang, Z. L., Fiber Supercapacitors made of Nanowire-Fiber Hybrid Structures for Wearable/Flexible Energy Storage. Angew. Chem. Int. Ed 2011, 50, 1683-1687.

15. Kou, L.; Huang, T.; Zheng, B.; Han, Y.; Zhao, X.; Gopalsamy, K.; Sun, H.; Gao, C., Coaxial Wet-Spun Yarn Supercapacitors for High-Energy Density and Safe Wearable Electronics. Nat. Commun. 2014, 5, 3754.

16. Liu, L.; Yu, Y.; Yan, C.; Li, K.; Zheng, Z., Wearable Energy-Dense and Power-Dense Supercapacitor Yarns Enabled by Scalable Graphene-Metallic Textile Composite Electrodes. Nat. Commun. 2015, 6, 7260.

17. Shen, L.; Du, L.; Tan, S.; Zang, Z.; Zhao, C.; Mai, W., Flexible electrochromic supercapacitor hybrid electrodes based on tungsten oxide films and silver nanowires. Chem. Commun. 2016, 52, 62966299.

18. Xiong, G.; Meng, C.; Reifenberger, R. G.; Irazoqui, P. P.; Fisher, T. S., A Review of GrapheneBased Electrochemical Microsupercapacitors. Electroanalysis 2014, 26, 30-51.

19. Bissett, M. A.; Kinloch, I. A.; Dryfe, R. A. W., Characterization of $\mathrm{MoS}_{2}$-Graphene Composites for High-Performance Coin Cell Supercapacitors. ACS Appl. Mater. Interfaces 2015, 7, 17388-17398. 20. Peng, Z.; Lin, J.; Ye, R.; Samuel, E. L. G.; Tour, J. M., Flexible and Stackable Laser-Induced Graphene Supercapacitors. ACS Appl. Mater. Interfaces 2015, 7, 3414-3419.

21. Chee, W. K.; Lim, H. N.; Zainal, Z.; Huang, N. M.; Harrison, I.; Andou, Y., Flexible GrapheneBased Supercapacitors: A Review. J. Phys. Chem. C 2016, 120, 4153-4172.

22. El-Kady, M. F.; Shao, Y.; Kaner, R. B., Graphene for Batteries, Supercapacitors and Beyond. Nat. Rev. Mater. 2016, 1, 16033.

23. Wu, Z. S.; Parvez, K.; Winter, A.; Vieker, H.; Liu, X.; Han, S.; Turchanin, A.; Feng, X.; M??llen, K., Layer-By-Layer Assembled Heteroatom-Doped Graphene Films with Ultrahigh Volumetric Capacitance and Rate Capability for Micro-Supercapacitors. Adv. Mater. 2014, 26, 45524558.

24. Wu, Z. S.; Liu, Z.; Parvez, K.; Feng, X.; Müllen, K., Ultrathin Printable Graphene Supercapacitors with AC Line-Filtering Performance. Adv. Mater. 2015, 27, 3669-3675.

25. Li, N.; Yang, G.; Sun, Y.; Song, H.; Cui, H.; Yang, G.; Wang, C., Free-Standing and Transparent Graphene Membrane of Polyhedron Box-Shaped Basic Building Units Directly Grown 
Using a NaCl Template for Flexible Transparent and Stretchable Solid-State Supercapacitors. Nano Letters 2015, 15, 3195-3203.

26. Li, N.; Huang, X.; Zhang, H.; Shi, Z.; Wang, C., Graphene-hollow-cubes with network-faces assembled a 3D micro-structured transparent and free-standing film for high performance supercapacitors. J. Mater. Chem. A 2017, 5, 16803-16811.

27. Xu, C.; Xu, B.; Gu, Y.; Xiong, Z.; Sun, J.; Zhao, X. S., Graphene-Based Electrodes for Electrochemical Energy Storage. Energy Environ. Sci. 2013, 6, 1388-1388.

28. Zhao, X.; Zheng, B.; Huang, T.; Gao, C., Graphene-Based Single Fiber Supercapacitor with a Coaxial Structure. Nanoscale 2015, 7, 9399-9404.

29. Qu, G.; Cheng, J.; Li, X.; Yuan, D.; Chen, P.; Chen, X.; Wang, B.; Peng, H., A Fiber Supercapacitor with High Energy Density Based on Hollow Graphene/Conducting Polymer Fiber Electrode. Adv. Mater. 2016, 28, 3646-3652.

30. Meng, F.; Lu, W.; Li, Q.; Byun, J. H.; Oh, Y.; Chou, T. W., Graphene - Based Fibers: A Review. Adv. Mater. 2015, 27, 5113-5131.

31. Li, N.; Huang, X.; Zhang, H.; Shi, Z.; Li, Y.; Wang, C., NaCl multistage-recrystallizationinduced formation of 3D micro-structured ribbon-like graphene based films for high performance flexible/transparent supercapacitors. J. Mater. Chem. A 2017, 5, 14595-14603.

32. Li, N.; Yang, Q.; Liu, X.; Huang, X.; Zhang, H.; Wang, C., Controllable Synthesis of Tunable Microstructures of Self-Supporting Graphene Films from Opened Bubble to Cube via in Situ TemplateModulating. ACS Appl. Mater. Interfaces 2017, 9, 42093-42101.

33. Meng, Q.; Wu, H.; Meng, Y.; Xie, K.; Wei, Z.; Guo, Z., High-Performance All-Carbon Yarn Micro-Supercapacitor for an Integrated Energy System. Adv. Mater. 2014, 26, 4100-4106.

34. Kou, L.; Huang, T.; Zheng, B.; Han, Y.; Zhao, X.; Gopalsamy, K.; Sun, H.; Gao, C., Coaxial Wet-Spun Yarn Supercapacitors for High-Energy Density and Safe Wearable Electronics. Nat. Commun. 2014, 5, 3754.

35. Dong, Z.; Jiang, C.; Cheng, H.; Zhao, Y.; Shi, G.; Jiang, L.; Qu, L., Facile Fabrication of Light, Flexible and Multifunctional Graphene Fibers. Adv. Mater. 2012, 24, 1856-1861.

36. Meng, Y.; Zhao, Y.; Hu, C.; Cheng, H.; Hu, Y.; Zhang, Z.; Shi, G.; Qu, L., All-Graphene CoreSheath Microfibers for All-Solid-State, Stretchable Fibriform Supercapacitors and Wearable Electronic Textiles. Adv. Mater. 2013, 25, 2326-2331.

37. Sun, J.; Li, Y.; Peng, Q.; Hou, S.; Zou, D.; Shang, Y.; Li, Y.; Li, P.; Du, Q.; Wang, Z.; Xia, Y.; Xia, L.; Li, X.; Cao, A., Macroscopic, Flexible, High-Performance Graphene Ribbons. ACS Nano 2013, 7, 10225-10232.

38. Parvez, K.; Wu, Z. S.; Li, R.; Liu, X.; Graf, R.; Feng, X.; Müllen, K., Exfoliation of Graphite Into Graphene in Aqueous Solutions of Inorganic Salts. J. Am. Chem. Soc. 2014, 136, 6083-6091. 
39. Hummers, W. S.; Offeman, R. E., Preparation of Graphitic Oxide. J. Am. Chem. Soc. 1958, 80, 1339-1339.

40. Li, X.; Cai, W.; An, J.; Kim, S.; Nah, J.; Yang, D.; Piner, R.; Velamakanni, A.; Jung, I.; Tutuc, E.; Banerjee, S. K.; Colombo, L.; Ruoff, R. S., Large Area Synthesis of High Quality and Uniform Graphene Films on Copper Foils. Science 2009, 324, 1312-1314.

41. Nicolosi, V.; Chhowalla, M.; Kanatzidis, M. G.; Strano, M. S.; Coleman, J. N., Liquid Exfoliation of Layered Materials. Science 2013, 340, 1226419-1226419.

42. Chen, D.; Feng, H.; Li, J., Graphene Oxide: Preparation, Functionalization, and Electrochemical Applications. Chem. Rev. 2012, 112, 6027-6053.

43. Chabot, V.; Higgins, D.; Yu, A.; Xiao, X.; Chen, Z.; Zhang, J., A Review of Graphene and Graphene Oxide Sponge: Material Synthesis and Applications to Energy and the Environment. Energy Environ. Sci. 2014, 7, 1564-1564.

44. Li, Z.; Chu, J.; Yang, C.; Hao, S.; Bissett, M. A.; Kinloch, I. A.; Young, R. J., Effect of functional groups on the agglomeration of graphene in nanocomposites. Compos. Sci. Technol. 2018, $163,116-122$.

45. Abdelkader, A. M.; Cooper, A. J.; Dryfe, R. A. W.; Kinloch, I. A., How to get between the sheets: a review of recent works on the electrochemical exfoliation of graphene materials from bulk graphite. Nanoscale 2015, 7, 6944-6956.

46. Parvez, K.; Li, R.; Puniredd, S. R.; Hernandez, Y.; Hinkel, F.; Wang, S.; Feng, X.; Mullen, K., Electrochemically Exfoliated Graphene as Solution-Processable, Highly-Conductive Electrodes for Organic Electronics. ACS Nano 2013, 7, 3598-3606.

47. Cooper, A. J.; Wilson, N. R.; Kinloch, I. A.; Dryfe, R. A. W., Single Stage Electrochemical Exfoliation Method for the Production of Few-Layer Graphene via Intercalation of Tetraalkylammonium Cations. Carbon 2014, 66, 340-350.

48. Ambrosi, A.; Pumera, M., Electrochemically Exfoliated Graphene and Graphene Oxide for Energy Storage and Electrochemistry Applications. Chem. Eur. J. 2016, 22, 153-159.

49. Cao, J.; He, P.; Mohammed, M. A.; Zhao, X.; Young, R. J.; Derby, B.; Kinloch, I. A.; Dryfe, R. A. W., Two-Step Electrochemical Intercalation and Oxidation of Graphite for the Mass Production of Graphene Oxide. J. Am. Chem. Soc. 2017, 139, 17446-17456.

50. He, D.; Marsden, A. J.; Li, Z.; Zhao, R.; Xue, W.; Bissett, M. A., Fabrication of a GrapheneBased Paper-Like Electrode for Flexible Solid-State Supercapacitor Devices. J. Electrochem. Soc. 2018, 165, A3481-A3486.

51. Parvez, K.; Yang, S.; Feng, X.; Müllen, K., Exfoliation of Graphene via Wet Chemical Routes. Synth. Met. 2015, 210, 123-132.

52. Ferrari, A. C., Raman Spectroscopy of Graphene and Graphite: Disorder, Electron-Phonon Coupling, Doping and Nonadiabatic Effects. Solid State Commun. 2007, 143, 47-57. 
53. Ferrari, A. C.; Basko, D. M., Raman Spectroscopy as a Versatile Tool for Studying the Properties of Graphene. Nat. Nanotechnol. 2013, 8, 235.

54. Malard, L. M.; Pimenta, M. A.; Dresselhaus, G.; Dresselhaus, M. S., Raman Spectroscopy in Graphene. Phys. Rep. 2009, 473, 51-87.

55. Sing, K. S. W.; Everett, D. H.; Haul, R. A. W.; Moscou, L.; Pierotti, R. S.; Rouquerol, J.; Siemieniewska, T., Reporting Physisorption Data for Gas/Solid Systems with Special Reference to the Determination of Surface Area and Porosity. Pure \& Appl. Chem. 1985, 57, 603-619.

56. Chakraborty, S.; Colón, Y. J.; Snurr, R. Q.; Nguyen, S. T., Hierarchically Porous Organic Polymers: Highly Enhanced Gas Uptake and Transport Through Templated Synthesis. Chem. Sci. 2015, 6, 384-389.

57. Li, X.; Zhao, T.; Chen, Q.; Li, P.; Wang, K.; Zhong, M.; Wei, J.; Wu, D.; Wei, B.; Zhu, H., Flexible All Solid-State Supercapacitors Based on Chemical Vapor Deposition Derived Graphene Fibers. Phys. Chem. Chem. Phys. 2013, 15, 17752-17752.

58. Liang, Y.; Wang, Z.; Huang, J.; Cheng, H.; Zhao, F.; Hu, Y.; Jiang, L.; Qu, L., Series of InFiber Graphene Supercapacitors for Flexible Wearable Devices. J. Mater. Chem. A 2015, 3, 2547-2551. 59. Yang, C.; Shen, J.; Wang, C.; Fei, H.; Bao, H.; Wang, G., All-Solid-State Asymmetric Supercapacitor Based on Reduced Graphene Oxide/Carbon Nanotube and Carbon Fiber Paper/Polypyrrole Electrodes. J. Mater. Chem. A 2014, 2, 1458-1464.

60. Bae, J.; Park, Y. J.; Lee, M.; Cha, S. N.; Choi, Y. J.; Lee, C. S.; Kim, J. M.; Wang, Z. L., SingleFiber-Based Hybridization of Energy Converters and Storage Units Using Graphene as Electrodes. Adv. Mater. 2011, 23, 3446-3449.

61. Cheng, H.; Dong, Z.; Hu, C.; Zhao, Y.; Hu, Y.; Qu, L.; Chen, N.; Dai, L., Textile Electrodes Woven by Carbon Nanotube-Graphene Hybrid Fibers for Flexible Electrochemical Capacitors. Nanoscale 2013, 5, 3428-3428.

62. Hu, Y.; Cheng, H.; Zhao, F.; Chen, N.; Jiang, L.; Feng, Z.; Qu, L., All-In-One Graphene Fiber Supercapacitor. Nanoscale 2014, 6, 6448-6448.

63. Chen, Q.; Meng, Y.; Hu, C.; Zhao, Y.; Shao, H.; Chen, N.; Qu, L., $\mathrm{MnO}_{2}$-modified hierarchical graphene fiber electrochemical supercapacitor. J. Power Sources 2014, 247, 32-39.

64. Li, Y.; Sheng, K.; Yuan, W.; Shi, G., A High-Performance Flexible Fibre-Shaped Electrochemical Capacitor Based on Electrochemically Reduced Graphene Oxide. Chem. Commun. 2013, 49, 291-293.

65. Gopalsamy, K.; Xu, Z.; Zheng, B.; Huang, T.; Kou, L.; Zhao, X.; Gao, C., Bismuth Oxide Nanotubes-Graphene Fiber-Based Flexible Supercapacitors. Nanoscale 2014, 6, 8595-8595.

66. Le, V. T.; Kim, H.; Ghosh, A.; Kim, J.; Chang, J.; Vu, Q. A.; Pham, D. T.; Lee, J. H.; Kim, S. W.; Lee, Y. H., Coaxial Fiber Supercapacitor Using All-Carbon Material Electrodes. ACS Nano 2013, 7, 5940-5947. 
67. Huang, T.; Zheng, B.; Kou, L.; Gopalsamy, K.; Xu, Z.; Gao, C.; Meng, Y.; Wei, Z., Flexible High Performance Wet-Spun Graphene Fiber Supercapacitors. RSC Advances 2013, 3, 23957-23957. 

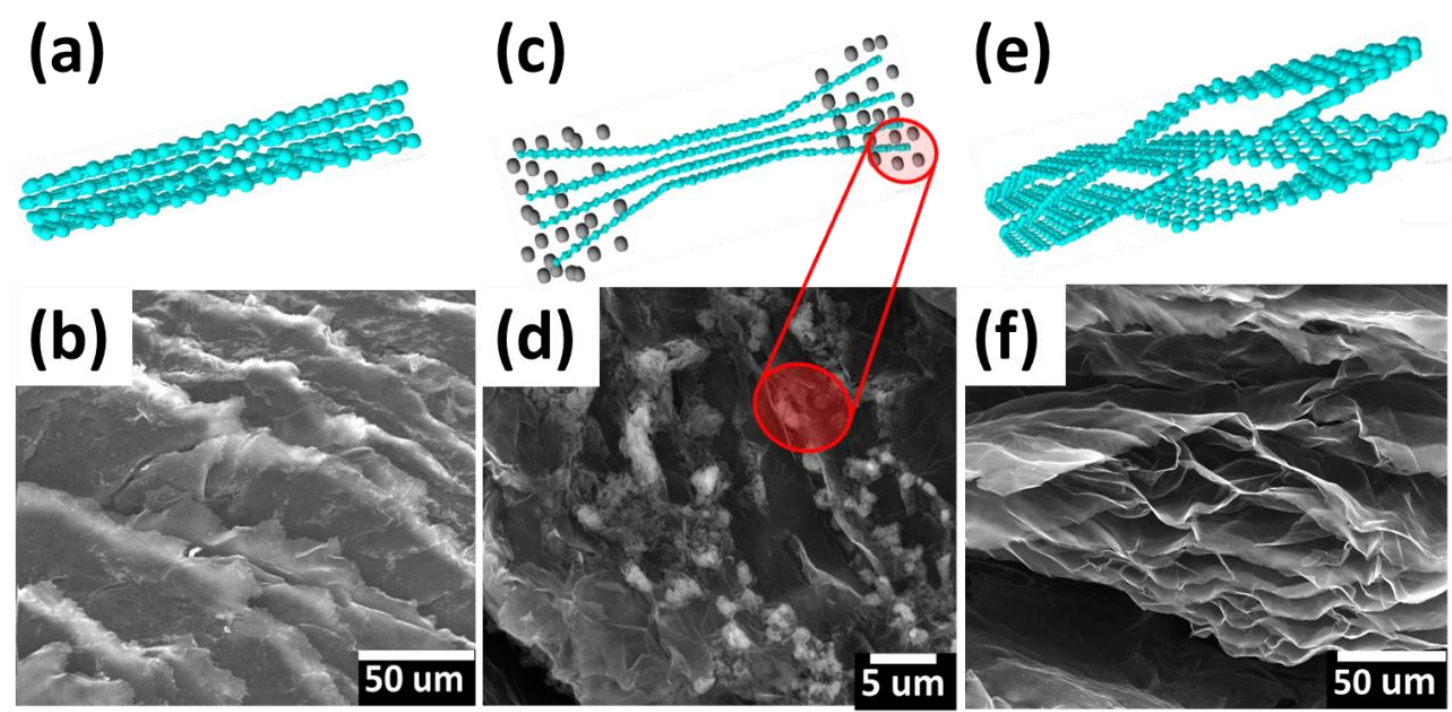

Figure 1. Schematic illustrating the electrochemical exfoliation process. (a) and (b) show the model structure and corresponding SEM image of the pristine graphite foil. (c) and (d) show the mechanism of the exfoliation process as well as the corresponding SEM image showing the partially expanded graphite (the light particles adhered on the edge are residual APS crystals). (e) and (f) show the model and corresponding SEM image of the final structure of the outer edge of the exfoliated graphene fibre. 


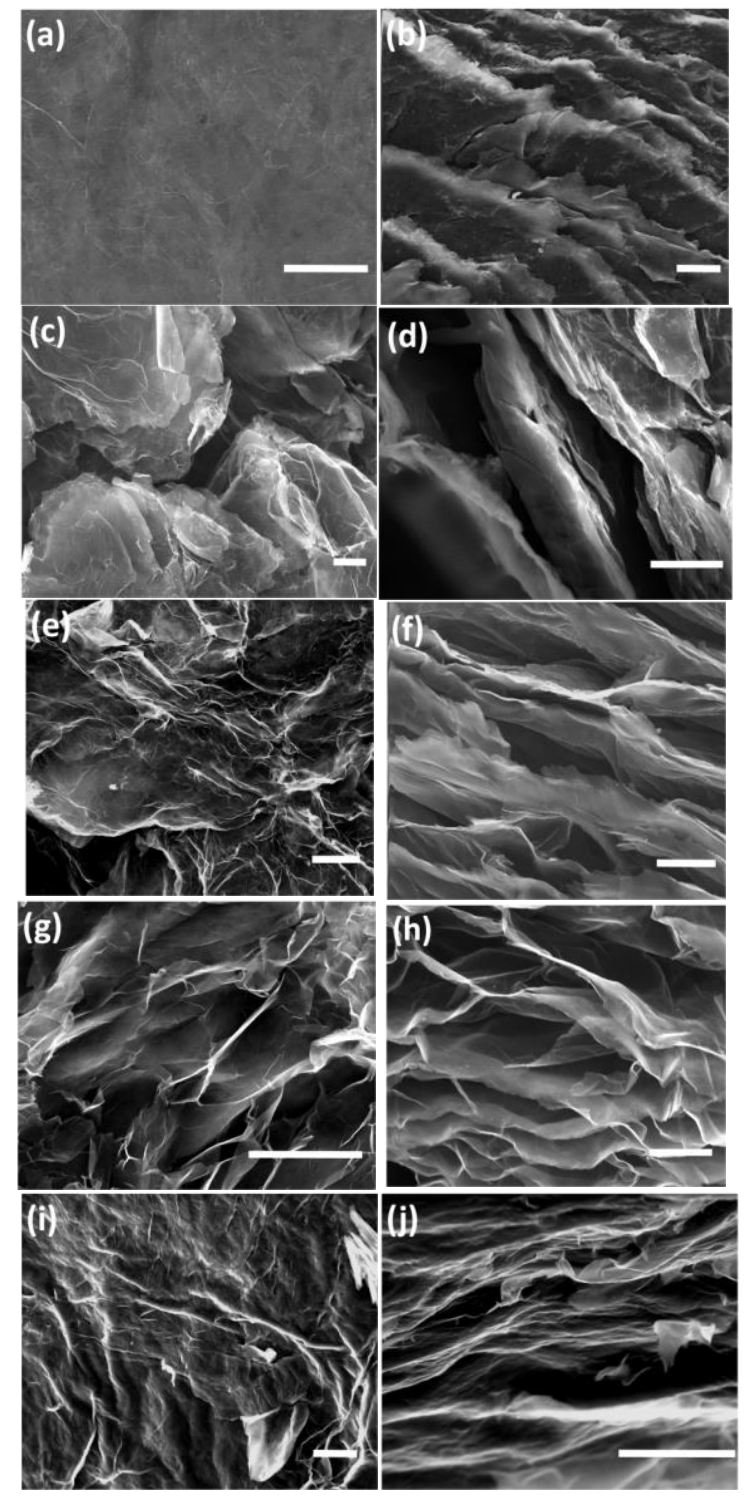

Figure 2. SEM images of the graphite fibres with increasing exfoliation time: GF0 (a, b); GF30 (c, d); GF60 (e, f); GF90 (g, h); and GF120 (i, j). The left column shows top down images taken of the surface and the right column shows cross section images taken from the side. The scale bar is $20 \mu \mathrm{m}$ for all images. 

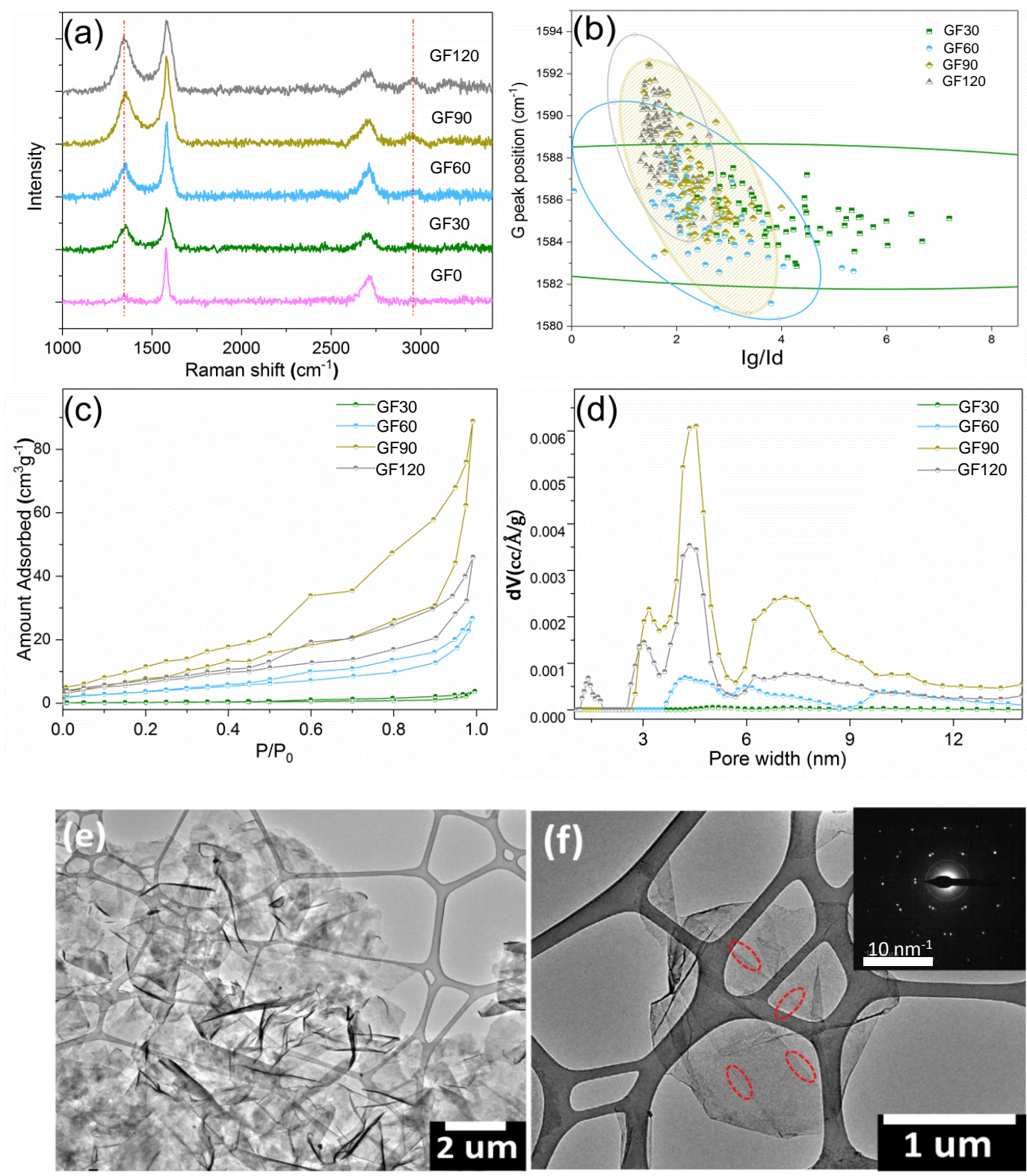

Figure 3. (a) Raman spectra of the exfoliated graphene fibres formed with different exfoliation times;

(b) the relationship between $I_{g} / I_{d}$ and G peak frequency (including the confidence ellipse). (c) Nitrogen adsorption and desorption isotherms; and (d) pore size distributions of the graphene fibres. TEM images: (e) TEM image of the GF90 sheets; (f) Magnified image of a GF90 sheet (red circles marked the edges of overlaps; inset is the SAED pattern of the flake). 

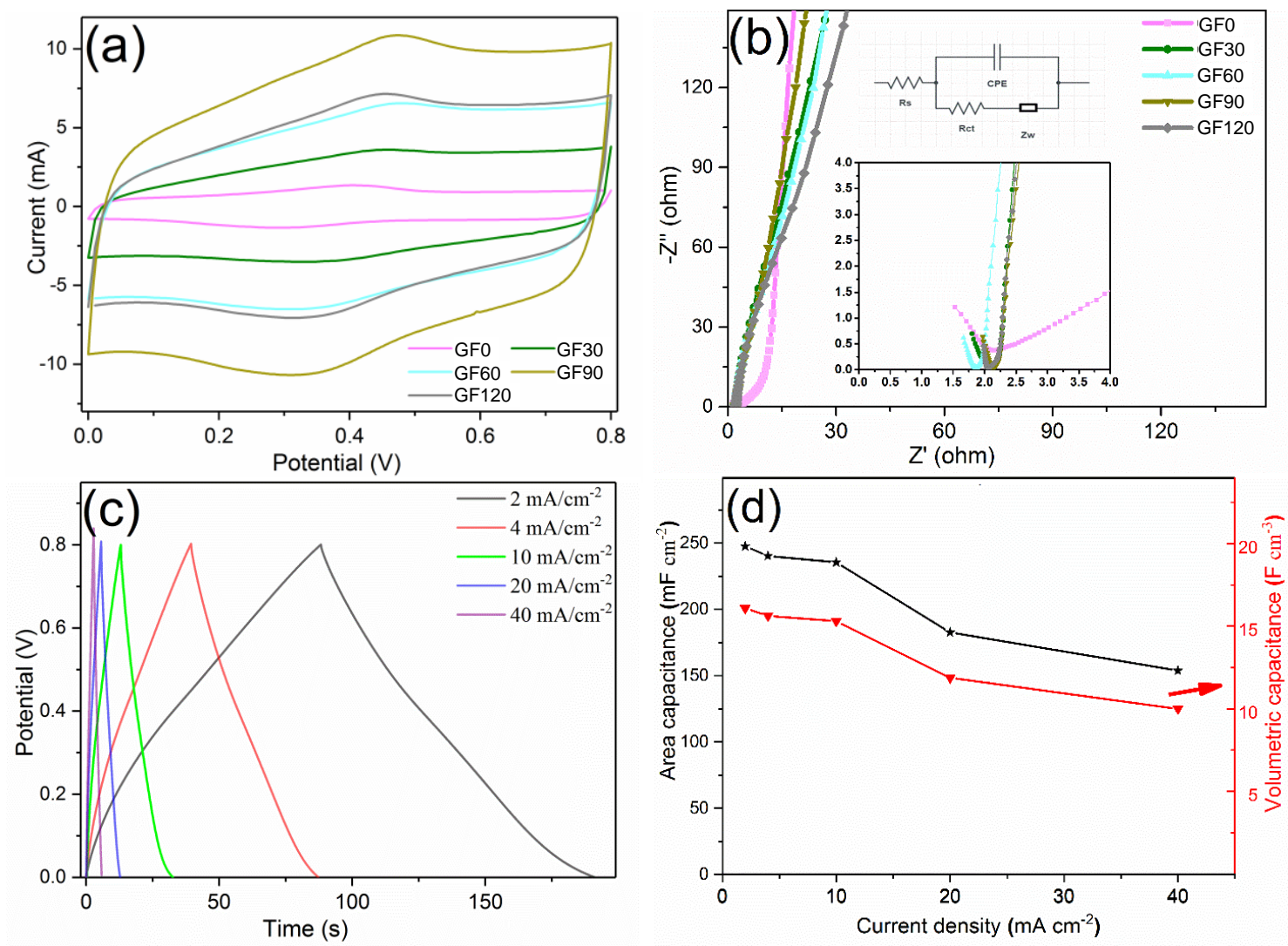

Figure 4. (a) Cyclic voltammograms ( $100 \mathrm{mVs}^{-1}$ scan rate) with $1 \mathrm{M} \mathrm{H}_{2} \mathrm{SO}_{4}$ electrolyte with increasing exfoliation times; (b) Nyquist plots of the different samples (insets are the magnified high frequency region and the equivalent circuit); (c) Galvanostatic charge-discharge curves of GF90 at different current densities; (d) Areal and volumetric capacitance of the GF90 with increasing current density. (All the measurement were carried out by using $\mathrm{Ag} / \mathrm{AgCl}$ as reference electrode.) 

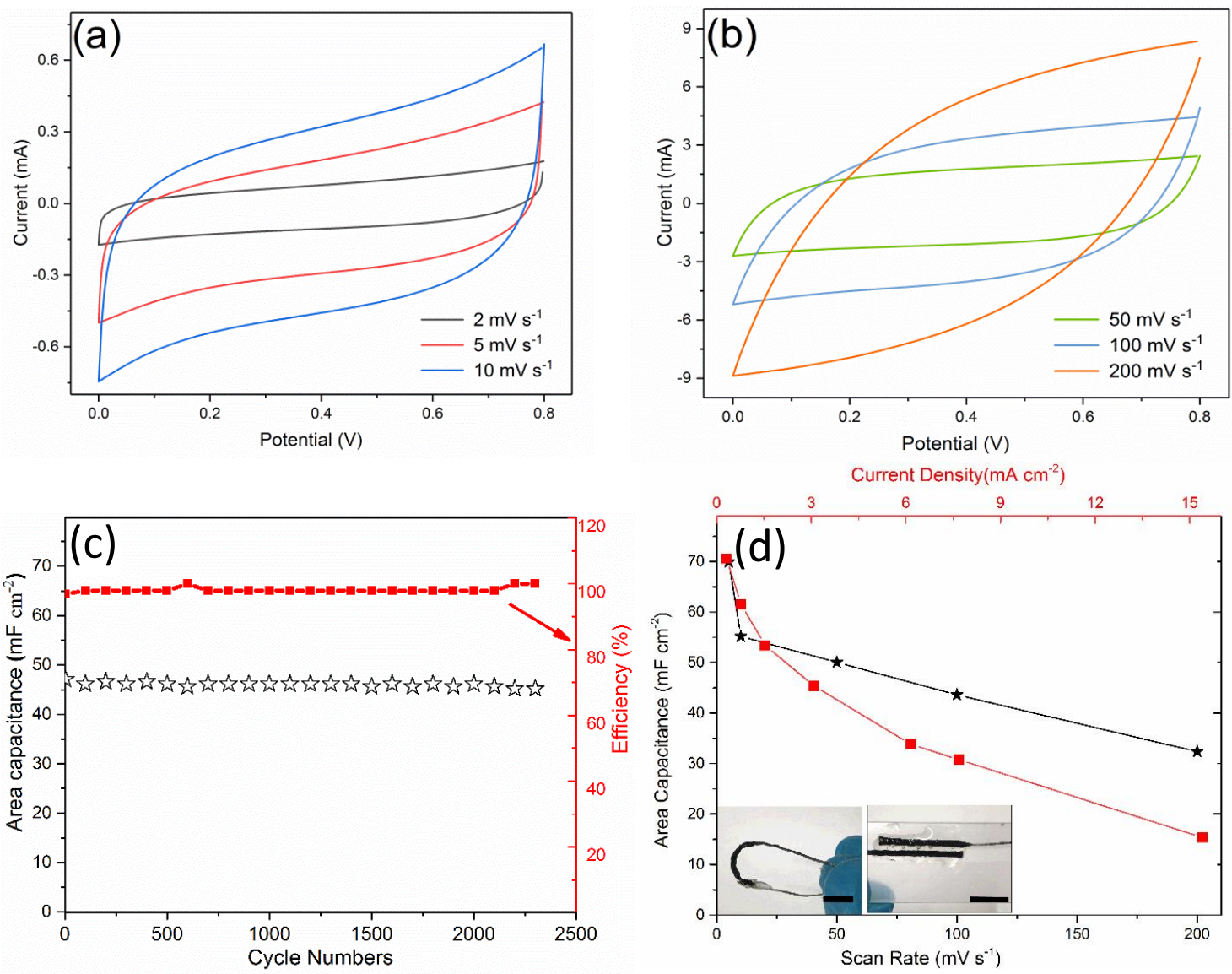

Figure 5. Electrochemical performance of the produced solid-state fibre supercapacitor. (a) and (b) CV curves at different scan rates. (c) Cycling performance and coulombic efficiency of the solid-state fibre supercapacitor.(d) Areal capacitance of the device with increasing scan rate and current density (inset are optical images showing two different devices with twisted and parallel structures (scale bar is $1 \mathrm{~cm}$ ). 
Table 1. Comparison of previously published related works on fibre-like supercapacitors.

\begin{tabular}{|c|c|c|c|c|c|}
\hline Ref & Electrode & Methods & Backbone & $\begin{array}{c}\text { Capacitance } \\
\text { (current density) }\end{array}$ & ESR \\
\hline 16 & rGO/ Ni cotton yarn & $\begin{array}{l}\text { Surface coating in } \\
\text { solution }\end{array}$ & Cotton yarns & $0.11 \mathrm{~F} \cdot \mathrm{cm}^{-1}$ & $17-25 \Omega$ \\
\hline 63 & $\mathrm{MnO}_{2} / \mathrm{rGO}$ & $\begin{array}{c}\text { Used a pipe as } \\
\text { template; } \\
\text { Electrodeposition }\end{array}$ & 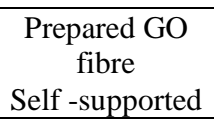 & $\begin{array}{c}9.6 \mathrm{mF} \cdot \mathrm{cm}^{-2} \\
\left(1.5 \mu \mathrm{A} \cdot \mathrm{cm}^{-1}\right)\end{array}$ & Not shown \\
\hline 29 & $\begin{array}{c}\text { graphene/conductive } \\
\text { polymer }\end{array}$ & $\begin{array}{l}\text { Used a pipe as } \\
\text { template; } \\
\text { Hydrothermal } \\
\text { method. }\end{array}$ & $\begin{array}{l}\text { Prepared rGO } \\
\text { fibre } \\
\text { Self-supported }\end{array}$ & $\begin{array}{c}\text { RGO hollow fibre: } 212.9 \\
\mathrm{mF} \cdot \mathrm{cm}^{-2}\left(0.1 \mathrm{~mA} \cdot \mathrm{cm}^{-2}\right) \\
\text { RGO/PEDOT:PSS fibre: } \\
304.5 \mathrm{mF} \cdot \mathrm{cm}^{-2}(0.3 \\
\left.\mathrm{mA} \cdot \mathrm{cm}^{-2}\right)\end{array}$ & $\begin{array}{l}605.4 \Omega \\
306.8 \Omega\end{array}$ \\
\hline 28 & rGO & $\begin{array}{l}\text { Wet-spinning; } \\
\text { dip-coating }\end{array}$ & $\begin{array}{c}\text { Prepared } \\
\text { coaxial } \\
\text { graphene fibre } \\
\text { Self-supported } \\
\end{array}$ & $205 \mathrm{mF} \cdot \mathrm{cm}^{-2}\left(1.1 \mathrm{~mA} \cdot \mathrm{cm}^{-2}\right)$ & $240 \Omega$ \\
\hline 15 & rGO/ MWCNT/ CMC & Wet-spinning & $\begin{array}{l}\text { Self-supported } \\
\text { structure }\end{array}$ & $177 \mathrm{mF} \cdot \mathrm{cm}^{-2}\left(0.1 \mathrm{~mA} \cdot \mathrm{cm}^{-2}\right)$ & $870 \Omega$ \\
\hline 66 & MWCNT & Spray method & $\begin{array}{c}\text { Carbon } \\
\text { microfibers }\end{array}$ & $\begin{array}{c}71.1 \mathrm{mF} \cdot \mathrm{cm}^{-2}(0.38 \\
\left.\mathrm{mA} \cdot \mathrm{cm}^{-2}\right)\end{array}$ & $4.2 \Omega \mathrm{cm}^{-1}$ \\
\hline 65 & $\mathrm{Bi}_{2} \mathrm{O}_{3}$ nanotube/ rGO & Wet-spinning & $\mathrm{Bi}_{2} \mathrm{O}_{3}$ nanotube & $\begin{array}{c}69.3 \mathrm{mF} \cdot \mathrm{cm}^{-2}(\text { single } \\
\text { electrode }) \\
17.3 \mathrm{mF} \cdot \mathrm{cm}^{-2}(\text { devices }) \\
\left(0.1 \mathrm{~mA} \cdot \mathrm{cm}^{-2}\right)\end{array}$ & $\begin{array}{l}600 \Omega \\
(\mathrm{RGO}) \\
1500 \Omega\end{array}$ \\
\hline 67 & $\mathrm{rGO} / \mathrm{PANI}$ & Wet-spinning & Self-supported & $\begin{array}{c}3.3 \mathrm{mF} \cdot \mathrm{cm}^{-2} \text { (graphene) } \\
66.6 \mathrm{mF} \cdot \mathrm{cm}^{-2}(\text { graphene- } \\
\text { PANI) }\left(0.1 \mathrm{~mA} \cdot \mathrm{cm}^{-2}\right)\end{array}$ & Not shown \\
\hline 57 & graphene & $\begin{array}{l}\text { CVD; Self- } \\
\text { assemble; } \\
\text { deposition }\end{array}$ & Self-supported & $\begin{array}{c}2.13 \mathrm{mF} \cdot \mathrm{cm}^{-2}(\text { graphene }) \\
42 \mathrm{mF} \cdot \mathrm{cm}^{-2} \\
\left(\text { graphene } / \mathrm{MnO}_{2}\right) \\
(10 \mathrm{mV} / \mathrm{s})\end{array}$ & $\sim 2000 \Omega$ \\
\hline 58 & rGO & $\begin{array}{l}\text { Wet-spinning; } \\
\text { laser irradiation }\end{array}$ & Self-supported & $14.3 \mathrm{mF} \cdot \mathrm{cm}^{-2}\left(50 \mathrm{~mA} \cdot \mathrm{cm}^{-3}\right)$ & Not shown \\
\hline 62 & rGO & $\begin{array}{l}\text { Spinning method; } \\
\text { laser irradiation }\end{array}$ & Self-supported & $2.4 \mathrm{mF} \cdot \mathrm{cm}^{-2}\left(0.8 \mathrm{~mA} \cdot \mathrm{cm}^{-2}\right)$ & Not shown \\
\hline 60 & Graphene & CVD & $\mathrm{Cu}$ mesh & $0.4 \mathrm{mF} \cdot \mathrm{cm}^{-2}(100 \mathrm{mV} / \mathrm{s})$ & Not shown \\
\hline 64 & rGO & Electrodeposition & Au wire & $6.5 \mathrm{mF} \cdot \mathrm{cm}^{-2}$ & $\begin{array}{c}19.5 \Omega \\
0.92 \Omega \cdot \mathrm{cm}^{-2}\end{array}$ \\
\hline 36 & rGO & $\begin{array}{l}\text { Hydrothermal } \\
\text { method; } \\
\text { Used a pipe as } \\
\text { template. }\end{array}$ & $\begin{array}{l}\text { Prepared } \\
\text { graphene fibre }\end{array}$ & $1.7 \mathrm{mF} \cdot \mathrm{cm}^{-2}\left(17 \mu \mathrm{A} \cdot \mathrm{cm}^{-2}\right)$ & Not shown \\
\hline $\begin{array}{l}\text { This } \\
\text { work }\end{array}$ & Graphene & $\begin{array}{c}\text { Electrochemical } \\
\text { exfoliation }\end{array}$ & $\begin{array}{c}\text { Self- } \\
\text { supported }\end{array}$ & $\begin{array}{c}247.6 \mathrm{mF} \cdot \mathrm{cm}^{-2} \\
\text { (three-electrode system) } \\
\left(2 \mathrm{~mA} \cdot \mathrm{cm}^{-2}\right) \\
70.6 \mathrm{mF} \cdot \mathrm{cm}^{-2} \\
\text { (Solid-state device) }(0.3 \\
\left.\mathrm{mA} \cdot \mathrm{cm}^{-2}\right)\end{array}$ & $\begin{array}{c}2.4 \Omega \\
\text { (three- } \\
\text { electrode } \\
\text { system) } \\
\sim 27.4 \Omega \\
\text { (Solid-state } \\
\text { device) }\end{array}$ \\
\hline
\end{tabular}

